\title{
PRECAUÇÕES NOS CASOS DE ÓBITO POR COVID 19 EM INSTITUIÇÃO DE LONGA PERMANÊNCIA PARA IDOSOS (ILPI)
}

Cássia Rozária da Silva Souza'

ORCID: 0000-0001-9790-3713

Cristiane dos Santos Rosa"

ORCID: 0000-0002-6001-7053

Josiani Nunes do Nascimento"'" ORCID: 0000-0001-6841-9551

Lucimar de Souza Camposiv ORCID: 0000-0002-2863-5337

Marianina Cerbina Grisi Pessoa Costav ORCID: 0000-0002-6065-1628

'Escola Superior de Ciências da Saúde da Universidade do Estado do Amazonas (ESA/UEA). Manaus, Amazonas, Brasil.

"ILPI- Espaço Vianney. Rio de Janeiro-RJ. Brasil.

'"HPS Dr. João Lúcio Machado. Coordenadora da Comissão de Controle de Infecção Hospitalar. Manaus, Amazonas, Brasil.

IVLar de Convivência Iclea de Sá - Lar Jolie. Rio de Janeiro, Rio de Janeiro, Brasil.

${ }^{\vee}$ Hospital Universitário Getúlio Vargas (HUGV) da Universidade Federal do Amazonas (UFAM). Manaus, Amazonas, Brasil.

Autor Correspondente: Cássia Rozária da Silva Souza E-mail:crsouza@uea.edu.br

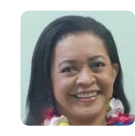

Como citar:

Souza CRS, Rosa CS, Nascimento JN, Campos LS, Costa MCGP. Precauções nos casos de óbito por covid 19 em instituição de longa permanência para idosos. In: Santana RF. Enfermagem gerontologica no cuidado do idoso em tempos da COVID 19. 2.ed.rev. Brasilia, DF: Editora ABEn; 2020.

p. 44-48. (Serie Enfermagem e Pandemias, 1). https://doi.org/10.51234/aben.20.e01.c07

\section{INTRODUÇÃO}

Uma das maiores dores que a Covid 19 está causando em todo o mundo, é a de não poder se despedir de seus entes queridos. Além de todo o processo de adoecimento, distanciamento e perda, ainda há o sofrimento gerado pela não despedida. É aquele momento em que se olha para o familiar e se tenta guardar todos seus traços físicos, associado à lembrança de quem ele era. Isso faz parte do luto, que ora, agora se configura de outra maneira, tornando mais dolorosa essa perda sem despedida.

Em direção a esse novo cenário, tem-se à necessidade de apresentação de um substrato que auxilie a partir desse momento, da perda da pessoa idosa. Todo o material foi embasado nas diretrizes do Ministério da Saúde e, busca além de direcionar os procedimentos e trâmites necessários para o sepultamento da pessoa idosa, orientar os profissionais como efetivar tais ações junto ao corpo, familiares e funerária ${ }^{(1,2)}$.

\section{OBJETIVO}

Orientar profissionais, familiares e funerárias no processo de morte da pessoa idosa institucionalizada pela COVID-19.

\section{MÉTODO}

Para trazer esta produção global de conhecimento para o ambiente das ILPIs, tendo como ponto focal o preparo do corpo do idoso, traçamos como metodologia uma análise documental reflexiva de normativas, $\mathrm{RDCs}$, manuais e outros documentos oficiais produzidos entre Janeiro à abril de 2020, para oferecer subsídios para que o profissional efetue de forma segura para si e para os demais sem perder o caráter humanístico em que permeia o cuidado ao fim de vida.

As ações foram divididas em que contemplou desde o momento do óbito atestado até o sepultamento, sendo essas: a) Preparação e acondicionamento do corpo para transferência do quarto; b) Transladação do corpo e c) Orientações para a assistência funerária. 


\section{RESULTADOS}

Nos casos que o idoso já está diagnosticado ou com suspeita de Covid 19, os protocolos recomendados de segurança devem ser seguidos e, os idosos colocados em isolamento ${ }^{(3)}$. Devendo a ILPI preparar quartos de isolamento e quando houver estruturação física, um isolamento para quadros graves.

\section{Preparação e acondicionamento do corpo}

Quando o idoso vai a óbito, há diferentes fases com procedimentos que precisam ser realizados, sendo agregados por etapas distintas, a começar com a Preparação e acondicionamento do corpo para transferência do quarto (Quadro 1).

O Quadro 2 apresenta os cuidados com Transladação do corpo e Orientações para a assistência funerária.

A elaboração do fluxograma 1 visa sistematizar e auxiliar a tomada de decisão pelos profissionais presentes no momento do ocorrido, considerando, que nem sempre as ILPIs possuem um número suficientes de profissionais e condições estruturais que facilitem as ações a serem implementadas. Portanto, direcionar as ações antecipadamente, diminuiria os possíveis riscos de contaminação do profissional, do ambiente e otimizaria o tempo da equipe envolvida.

Quadro 1 - Preparação e acondicionamento do corpo para transferência do quarto.

- O preparo e o manejo apressados de corpos de pacientes com COVID-19 devem ser evitados, mantendo a ética e profissionalismo exigido para aquele momento ${ }^{(4)}$;

- Durante os cuidados com o corpo, só devem estar presentes no quarto os profissionais estritamente necessários;

- Os profissionais que devem utilizar os EPIs: os profissionais que tiverem contato com o corpo, devendo usar gorro, óculos de proteção e protetor facial (face shield), máscara cirúrgica (usar N95, PFF2 ou equivalente), avental ou capote (usar capote ou avental impermeável caso haja risco de contato com volumes de fluidos ou secreções corporais) e 2 pares de luvas (usar luvas nitrílicas para o manuseio durante todo o procedimento); botas impermeáveis.

- Higienizar as mãos antes e depois da interação com o corpo e o meio ambiente;

- Descartar imediatamente os resíduos pérfuro-cortantes em recipientes rígidos, à prova de perfuração e vazamento e com o símbolo de resíduo infectante;

- Tampar/bloquear orifícios naturais do corpo (oral, nasal, retal) para evitar extravasamento de fluidos corporais;

- A movimentação e manipulação do corpo deve ser a menor possível;

- Acondicionar o corpo em saco impermeável, à prova de vazamento e selado;

- Quando possível, a embalagem do corpo deve seguir três camadas:

$1^{\text {a: }}$ enrolar o corpo com lençóis;

$2^{\mathrm{a}}$ : colocar o corpo em saco impermeável próprio (esse deve impedir que haja vazamento de fluidos corpóreos); $3^{a}$ : colocar o corpo em um segundo saco (externo) e desinfetar com álcool a $70 \%$, solução clorada $0,5 \%$ a $1 \%$ ou outro saneante regularizado pela ANVISA, compatível com o material do saco. Colocar etiqueta com identificação do corpo.

- Desprezar as luvas que foram usadas em local adequado;

- Desinfetar a superfície externa do saco (pode utilizar álcool líquido a 70\%, solução clorada [0.5\% a 1\%], ou outro saneante desinfetante regularizado junto a ANVISA, tomando-se cuidado de não usar luvas contaminadas para a realização desse procedimento;

- Identificar o saco com o corpo, incluindo as informações relativas ao risco biológico, no contexto da COVID-19: agente biológico classe de risco 3.

Toda a rouparia que era de uso do idoso deve ser colocada em um saco, lacrado e identificado para desprezar. A paramentação e desparamentação deve seguir os protocolos recomendados ${ }^{10}$, sendo iniciado próximo a saída da área de isolamento, deixando somente a máscara para ser retirada fora desta área na seguinte ordem:

A) Paramentação:

1.Avental ou capote: nuca amarrando-o na parte da frente;

2. Máscara N95, PFF2, Cirúrgica;

3. Gorro;

4. Óculos de proteção ou face Shield;

5. Por último dois pares de luvas; 
B)Desparamentação:

1.Primeiro par de luvas: durante a retirada das luvas não toque a parte externa pois estarão contaminadas, higienize as mãos com álcool 70\%;

2.Retire o avental ou capote: não toque na parte externa, retirar sem movimentos bruscos de forma que a parte externa fique envolvida pela interior;

3.Retire o segundo par de luvas;

4.Higienize mão com álcool 70\%;

5.Retire o gorro;

6.Retire o óculos de proteção ou protetor facial;

7.Higienize as mão com álcool 70\%;

8.Retire a máscara.

9.Lave as mão com agua e sabão;

Os EPIs descartáveis devem ser em recipiente para resíduo contaminante.

Quanto aos pertences pessoais como joias e lembranças da família, devem ser higienizados antes de entregar à família com álcool a $70 \%$, solução clorada $0,5 \%$ a $1 \%$ ou outro saneante regularizado pela ANVISA .

A ocupação do quarto ou do ambiente só poderá ser feita após a limpeza terminal de objetos, mobiliário e estrutura física.

Quadro 2 - Orientações para a assistência funerária-Transladação do corpo

- Os profissionais que não tiverem contato com o corpo, mas apenas com o saco, deverão adotar as precauções padrão, higiene de mãos, avental ou capote e luvas;

- A maca de transporte de corpos deve ser utilizada apenas para esse fim e ser de fácil limpeza e desinfeção;

- quando houver a área de necrotério na ILPI o corpo deve ser removido para lá e evitar a entrada de qualquer pessoa que não seja da funerária.

Atenção: Não é recomendado que pessoas acima de 60 anos, com comorbidades (como doenças respiratórias, cardíacas, diabetes) ou imunosuprimidas sejam expostas a atividades relacionadas ao manejo direto do corpo.

- O serviço funerário/transporte deve ser informado de que o óbito se trata de vítima de COVID-19 (agente biológico classe de risco 3), além dos seguinte dados na etiqueta:

\section{COVID-19}

DATA

INSTITUIÇÃO:

PACIENTE:

DATA DE NASCIMENTO:

Idade:

PRONTUÁRIO

- Os profissionais que atuam no transporte, guarda e alocação do corpo no caixão também devem adotar as medidas de precaução como uso de luvas,aventais descartáveis e máscaras;

- Deve-se limpar a superfície da urna lacrada com solução clorada 0,5\%;

- Após a manipulação do corpo, retirar e descartar luvas, máscara, avental (se descartável) em lixo infectante;

- Após lacrada, a urna não poderá ser aberta;

- Não é necessário veículo especial para transporte do corpo;

- Devido ao atual contexto epidemiológico, caso haja funeral, deverá ocorrer com apenas 10 pessoas, limitado aos

familiares mais próximos para diminuir a probabilidade de contágio;

- Os participantes devem respeitar o distanciamento físico (de 2 metros), além de adotar o uso de máscara e realizar a higiene das mãos durante a cerimônia;

- O caixão deve ficar fechado durante todo o funeral, evitando contato físico com o corpo;

- O velório quando ocorrer deverá ter o tempo máximo de 1 hora;

- Devem estar disponíveis condições para a higiene das mãos de todos que participam do funeral (água e sabonete líquido e álcool em gel a 70\%);

- Os encarregados de colocar o corpo na sepultura ou em pira funerária devem usar luvas e desprezando as luvas ao final e higienizar as mãos com água e sabonete líquido,

O carro funerário deverá ser lavado no término do dia e poderá ser utilizado novamente, após sua higienização. 


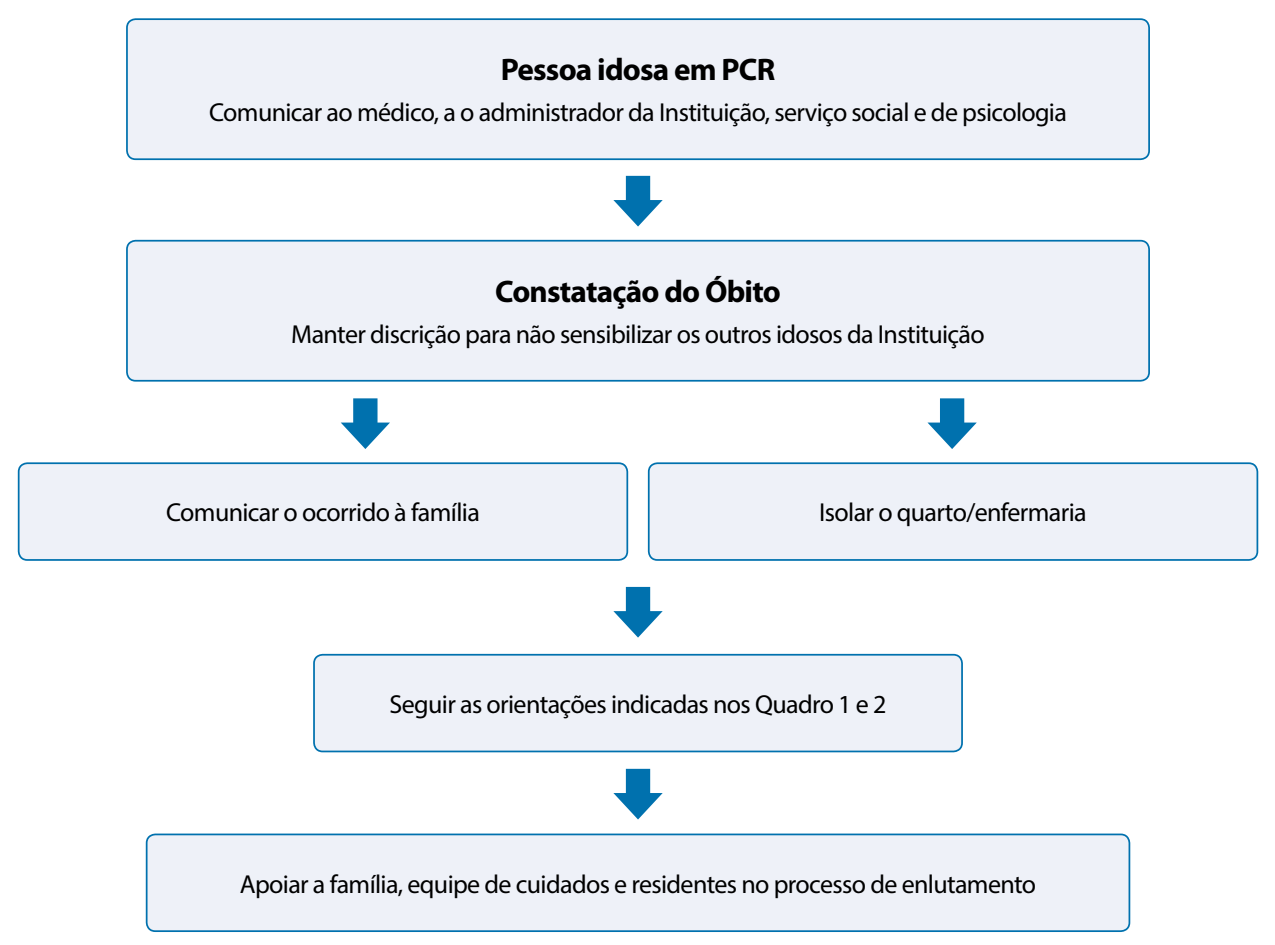

Figura 1: Fluxograma sugerido para ILPI em caso de óbito do idoso. Brasil, 2020.

Nesse sentido, a visão holística do cuidado, em sua maioria coordenado pelo profissional enfermeiro, em tempo de pandemia cabe pensar que o cuidado continua com o apoio e suporte a família do idoso, a equipe de cuidados e residentes da ILPI.

\section{Limitações}

Essa construção procurou manter um alinhamento em todas as fases do processo desencadeado até óbito frente à Covid 19, diante do novo panorama e um reduzido número de literatura disponível desde da manipulação do corpo contaminado até a orientação as funerárias, dentro dos parâmetros permitidos pela regulamentação vigente, da dignidade, cultura e religião dos familiares e da pessoa idosa que faleceu ${ }^{(7,8,9)}$.

\section{Contribuições para enfermagem}

Não se deve esquecer que a caracterização de uma ILPI é justamente o seu caráter residencial. Local onde as pessoas estabelecem vínculos, e apesar de todo um arcabouço legal que lhe impõe processos da área da saúde, essa não é resguardada. Hoje, a COVID-19, impõe inovações em tecnologias de cuidado para onde o toque terapêutico, a escuta sensível, o acolhimento devem ser reinventados. Em tempos triviais, a maior preocupação da equipe de cuidado é com a preservação emocional e mental dos demais idosos. Todavia, nesse novo cenário, lidar com o medo de se contaminarem, com a cobrança por regras rígidas de higiene, pelo distanciamento e com a morte sem o direito ao rituais fúnebres ocidentais tão importantes para o processo de enlutamento, impacta em cada um dos envolvidos 


\section{CONSIDERAÇÕES FINAIS}

A interrupção da vivência do luto, onde a família não pode fazer o velório ou se despedir de seu idoso, vêm gerando uma concepção de perda, sentimento esse ainda pouco pela sociedade e família. Em alguns países em decorrência ao grande número de óbitos, o sistema funerário entrou em colapso ocasionando grandes dificuldades na identificação e entrega dos corpos aos familiares, visando mitigar a possibilidade de extravio do corpo, aumentando assim o sofrimento da família, o cuidado com o processo de morte/morrer e o corpo post-mortem demonstram respeito e dignidade da pessoa idosa.

\section{AGRADECIMENTO}

\section{Ao Departamento Científico de Enfermagem Gerontológica da ABEn Nacional.}

\section{REFERÊNCIAS}

1. Ministério da Saúde. Manejo de corpos no contexto do novo coronavírus COVID-19. Secretaria de Vigilância em Saúde. Departamento de Análise em Saúde e Vigilância de Doenças não Transmissíveis. Brasília/DF. 1 ed. Versão 1. Publicada em 25/03/2020.

2. Protocolo de Manuseio de Cadáveres para Prevenção de Doenças Infecto Contagiosas de Notificação Compulsória, com Ênfase cm COVID-19 para o âmbito do Distrito Federal. Governo do Distrito Federal. Comissão de Criação de protocolo Mínimo de Enfrentamento em Casos de Óbitos no Âmbito do Distrito Federal.Versão 4, dia 26/03/2020.

3. Nota Técnica GVIMS/GGTES/ANVISA No 04/2020 - Orientações para Serviços de Saúde: Medidas de prevenção e controle que devem ser adotadas durante a assistência aos casos suspeitos ou confirmados de infecção pelo novo coronavírus (SARS-CoV-2). Gerência de Vigilância e Monitoramento em Serviços de Saúde. Gerência Geral de Tecnologia em Serviços de Saúde. Agência Nacional de Vigilância Sanitária - ANVISA. Atualizada em 31/03/2020.

4. Clos MB. Cuidados de idosos institucionalizados; o desafio da integralidade. Mais 60 Estudos sobre Envelhecimento. [internet] 2017[citado em 18 abril 2020]; 28 (69):24-39, dez. Disponível em: https://www.sescsp.org.br/files/ artigo/85b2b2b2/00b7/4910/a07e/19c9e601c272.pdf. Acesso em: 18 de abril de 2020.

5. Melo S. Recomendações para a gestão de resíduos em situação de pandemia por Coronavírus (COVID 19). 2020. Associação Brasileira de Engenharia Sanitária e Ambiental (ABES), março. Disponível em: http://abes-dn.org.br/ wp-content/uploads/2020/03/recomenda\%c3\%87\%c3\%95es-para-a-gest\%c3\%83o-de-res\%c3\%8dduos-emsitua\%c3\%87\%c3\%83o-de-pandemia-por-coronav\%c3\%8drus-covid-19-4.pdf. Acesso em: 18 de abril de 2020.

6. Ministério da Saúde (BR), Agência Nacional de Vigilância Sanitária. Resolução RDC/Anvisa n²22/2018. Regulamenta as Boas Práticas de Gerenciamento dos Resíduos de Serviços de Saúde e dá outras providências. Disponível em:http://portal. anvisa.gov.br/documents/10181/3427425/RDC_222_2018_.pdf/c5d3081d-b331-4626-8448-c9aa426ec410

7. Comunicação aos Trabalhadores de Enfermagem das Instituições de Longa Permanência de Idosos (ILPIs) para o Enfrentamento da Disseminação da Covid-19. Disponível em: http://www.abennacional.org.br/site/wp-content/ uploads/2020/03/DCEG-ABEn_Informe_COVID-19-ILPI.pdf. Acesso em: 18 de abril de 2020.

8. Malar JP. Do medo da morte ao luto, como lidar com os efeitos psicológicos do novo coronavírus?Disponível em: http://www.ip.usp.br/site/noticia/do-medo-da-morte-ao-luto-como-lidar-com-os-efeitos-psicologicos-do-novocoronavirus/.2020. Acesso em: 18 de abril de 2020.

9. Souza CP e Souza AM. Rituais Fúnebres no Processo do Luto: Significados e Funções. Psic.: Teor. e Pesq. [online]. 2019, v.35, e35412. EPUB, July 04, 2019. ISSN 0102-3772. Disponível em: https://doi.org/10.1590/0102.3772e35412. Acesso em: 18 de abril de 2020.

10. Cofen.Covid 19.Orientações Sobre a Colocação e retirada dos Equipamentos de proteção individual(EPI).Disponível em https://www.cofen.org.br 